\title{
Automatic Book Placement and Searching Technique for Performance Enhancement of Library Management System
}

\author{
Umar Farooq, Muhammad Amar, K. M. Hasan, Muhammad Usman Asad and Asim Iqbal
}

\begin{abstract}
This paper describes a book placement and book searching method for performance enhancement of existing library systems in Pakistan. The book placement mechanism is used to ensure the placement of book inside the shelf according to assigned code to facilitate manual searching. The prototype system uses a web camera to capture the title page of the book. The image is processed to extract the title of the book which is passed to the database for getting book reference number. Control commands for cartesian robot are then generated to place the book inside the shelf. Book searching is carried out with the help of mobile phone software developed using NetBeans IDE integrated with Java Wireless Toolkit. The user can search the desired book either by providing title of book or its author name. The software returns the reference number containing book code and shelf number describing location of the book. The user can send this reference number to library station to check the availability of the book using SMS service of GSM network. The base station then responds with issuance and return dates of the desired book.
\end{abstract}

Index Terms-library management system, mobile phone based book searching, GSM based book status enquiry, text recognition based book placement

\section{INTRODUCTION}

Libraries are the source of knowledge and wisdom, but with the increasing education branches and new researches, million of the books are being added to libraries. Manual sorting and placement of these books in shelves is a time consuming and cumbersome process for humans. This often results in incorrect placement of books on shelves. Consequently people find it difficult to locate the book because the exact location of book returned by the database differs from its present location. Thus an efficient and automatic book placement system is required to facilitate the people in locating the desired book in a short period of time. The question then arises to which information is necessary to automate the system. The front cover of the book contains information such as the title of the book, edition of book, name of authors and also publisher name in some cases.

Manuscript received December 20, 2009.

Umar Farooq, Muhammad Amar, Muhammad Usman Asad and Asim Iqbal are with Department of Electrical Engineering, University of The Punjab Lahore 54590 Pakistan. (corresponding author phone: +923217264147; e-mail: engr.umarfarooq@yahoo.com).

K. M. Hasan is with Department of Electrical Engineering University of Engineering and Technology Lahore 54890 Pakistan (e-mail: kmhasan@uet.edu.pk).
Among all these parameters, it is easy to extract the title of the book owing to the property of being largest in font size. Thus the problem domain for book placement task is 'extraction and recognition of text data embedded in images'. In addition, conventional libraries provide limited number of keyboards and displays for searching the database. As a result, the people have to wait in queue for searching the desired book. If the book is not available or issued to some other person, then more time is wasted. A distant search mechanism is therefore desired so that the users get information regarding the availability of book and its location inside the library without coming to the library thereby saving the traveling time in case of non-availability.

In this paper, book search software using NetBeans IDE and book placement system using image processing is developed. In order to search a particular book, the user has to enter the title of book or its author(s) name. The reference number returned by the software is sent to library station for checking the availability of the book. The station responds by sending back the issuance and return dates of the book. For this search system to be useful, an automatic placement mechanism is developed to ensure the exact placement of the book inside the shelf according to the assigned code number. In this mechanism, digital camera captures the image of the title page of the book. The title of the book is extracted and searched in database for reference number. Using this reference number, the designed algorithm controls the axis motors accordingly for placing the book inside the shelf.

\section{RELATED WORK}

In [1], Hideaki Araki has developed a library system augmented by ubiquitous computing. The system uses a combination of CCD cameras and infrared sensors to identify which book is removed from the shelf and updates the book storage database. In [2], Shamsudin has proposed radio frequency identification (RFID) based intelligent shelving system as an efficient mechanism of books management monitoring through wireless communication between the RFID reader and the books to alleviate the intensive labors and efforts in shelving the books. RFID-based systems has also been used as tracking systems that combine security with more efficient tracking of materials throughout the library, including easier and faster charge and discharge, inventorying, and materials handling [3,4,5]. In [6], Markus Aittola has developed a location aware mobile library service, Smart Library that provides map based guidance to books and collections on PDA. But this will require the books 
to be correctly placed inside the shelves. Although efficient, these systems provide a costly solution for library book search and placement tasks. A relatively low cost solution is presented in this paper for book placement and searching. Book placement task is based on text extraction and recognition from the captured front cover of the book while book searching is carried out with the help of mobile software developed using NetBeans IDE integrated with J2ME wireless toolkit. When implemented in real time, the designed systems are found to be effective. The block diagram of the system is shown in Fig. 1.

\section{MeChaniCAL System DeSIGN}

\section{A. Structure Design}

Rectangular coordinated motion is used in designing the system. Three DC motors are used to control the motion along three axes namely $\mathrm{X}, \mathrm{Y}$ and $\mathrm{Z}$-axis. The structure comprises of two rectangular frames. One rectangular frame is controlling $\mathrm{X}$ and $\mathrm{Y}$-axis motion while the second frame is used for motion along $\mathrm{Z}$-axis. $\mathrm{X}$ and $\mathrm{Y}$-axis motion shifts the book to the desired place in front of shelve and Z-axis motion places the book inside the shelf. The prototype is shown in Fig. 2.

\section{B. Material}

Mechanical structure is built from iron metal therefore it is capable of bearing load of heavy books. Angle Iron is used for construction of frame and circular rods are used for the vertical and horizontal motion of the base placed on spindles.

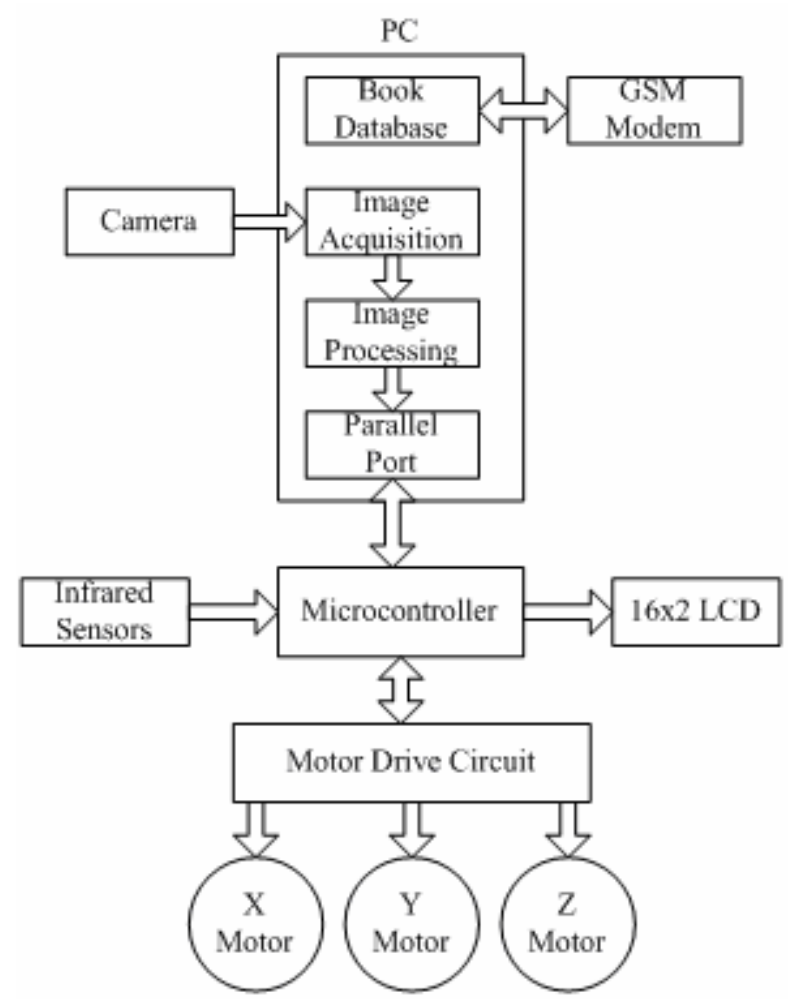

Figure 1. Block Diagram of Proposed System

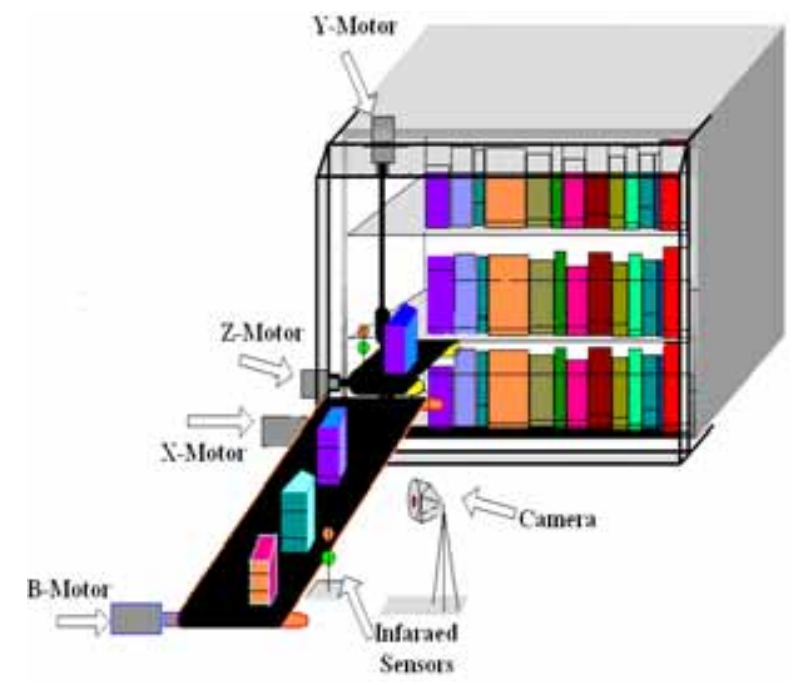

Figure 2. System Prototype

\section{Spindle Action}

For the forward \& reverse motion of base, spindle mechanism is used. A motor is connected to one end of threaded rod and internally thread square shape base move forward and backward as the rod rotates. When the motor rotates in clockwise direction, the vertical mechanism moves towards the motor and in counter-clockwise direction, it moves away from the motor.

\section{Book Placement}

One of the major tasks was to place the book in the shelf automatically. For this, a base floor is designed comprising of a sliding mechanism as shown in Fig. 3. Highlighted region show that arrangement is placed on the iron sheet. Bearings are connected with U-shape angle to avoid any misplacement. When $\mathrm{X}$ and $\mathrm{Y}$-axis rods stop at destination point, the rods of this mechanism start to rotate and book is placed inside the wooden shelf.

\section{ElECTRICAL SySTEM DESIGN}

\section{A. GSM Modem}

A wireless link between the library user and library database is provided with Nokia $12 \mathrm{i}$ GSM module. Nokia $12 \mathrm{i}$ offers advance GSM connectivity and supports EDGE/GPRS and HSCSD with automated GSM connection establishment It is equipped to provide reliable remote connections and offers application level watchdogs, inbuilt self check mechanisms and a reliable Virtual Machine (VM) for $\mathrm{JAVA}^{\mathrm{TM}}$. Nokia $12 \mathrm{i}$ also supports reliable inbuilt internet protocols: TCP/IP for reliable data transfer, UDP/IP for audio and video streaming and HTTP for accessing web pages. External microprocessor can use AT commands to communicate with Nokia $12 \mathrm{i}$ and simple remote $\mathrm{I} / \mathrm{O}$ applications can easily be controlled via text messages [7].

\section{B. Microcontroller}

AT89C51 microcontroller is selected because it is a powerful microcomputer which has low power consumption and provides a highly flexible and cost-effective solution to many embedded control applications. It has $4 \mathrm{~K}$ bytes of in 
system reprogrammable flash memory, 128 bytes of internal RAM, 32 programmable I/O lines, two 16 bit timers/counters, seven interrupt sources and a programmable serial channel. Microcontroller transmits sensor information to $\mathrm{PC}$ and receives motor commands from $\mathrm{PC}$ on its port 2 (P2) [8]. The microcontroller is programmed in $\mathrm{C}$ using Keil development platform [9].

\section{Infrared Sensors}

An infrared sensor consisting of two transmitters LED's and a GP1U52 receiver [10] is mounted on base shelf to detect the presence of book. Two LED's are used in transmitter for increasing the transmitted signal power. The transmitters LED's are modulated at $40 \mathrm{kHz}$ to avoid interference effects from common indoor lighting sources like florescent lights. The output signal from GP1U52 IR receiver varies from $1.7 \mathrm{v}$ (no signal) to $2.5 \mathrm{v}$ (strong signal) which is not suitable for microcontroller having digital I/O's. The signal is therefore converted into $0-5 \mathrm{v}$ range by using LM311 operational amplifier as comparators and fed to P3.0 of microcontroller. The circuit diagram is shown in Fig. 3.

\section{D. $L C D$}

An optrex 16x2 LCD [11] is used for displaying the number of books placed inside the shelf by $\mathrm{CNC}$ mechanism. Eight bit data bus of LCD is connected to P1 of microcontroller while control lines, enable and register select, are connected to $\mathrm{P} 3.1$ and $\mathrm{P} 3.2$ respectively.

\section{E. Motor Interface Circuit}

This interface circuit utilizes three L298N IC's to drive the motors along three axes. L298N contains two built-in $\mathrm{H}$-bridges each one has a current carrying capacity of $2 \mathrm{~A}$. To increase the current rating, the two bridges are connected in parallel enhancing it to 4A [12]. The interface circuitry also contains opto-couplers, $4 \mathrm{~N} 25$ to isolate the inductive effects of motors from microcontroller. L298N can also sense the current drawn by motors. This feature is utilized to design overload protection circuit using operational amplifiers. A total of 12 bits are required for interfacing motor driver and protection circuits to microcontroller. Ports, P0 and P3.3-P3.6, of microcontroller are used for this purpose. In case of overloading, microcontroller shuts off the motors and turns on the alarm. The motor interface circuit with one channel is shown in Fig. 4.

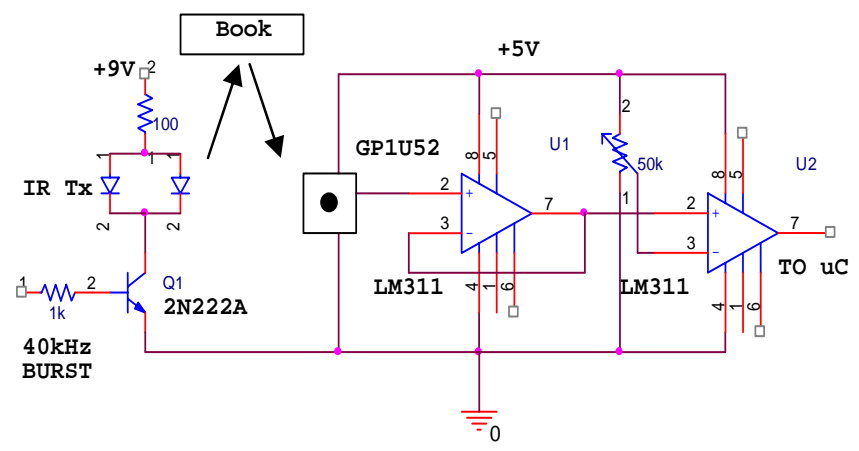

Figure 3. Infrared Sensor

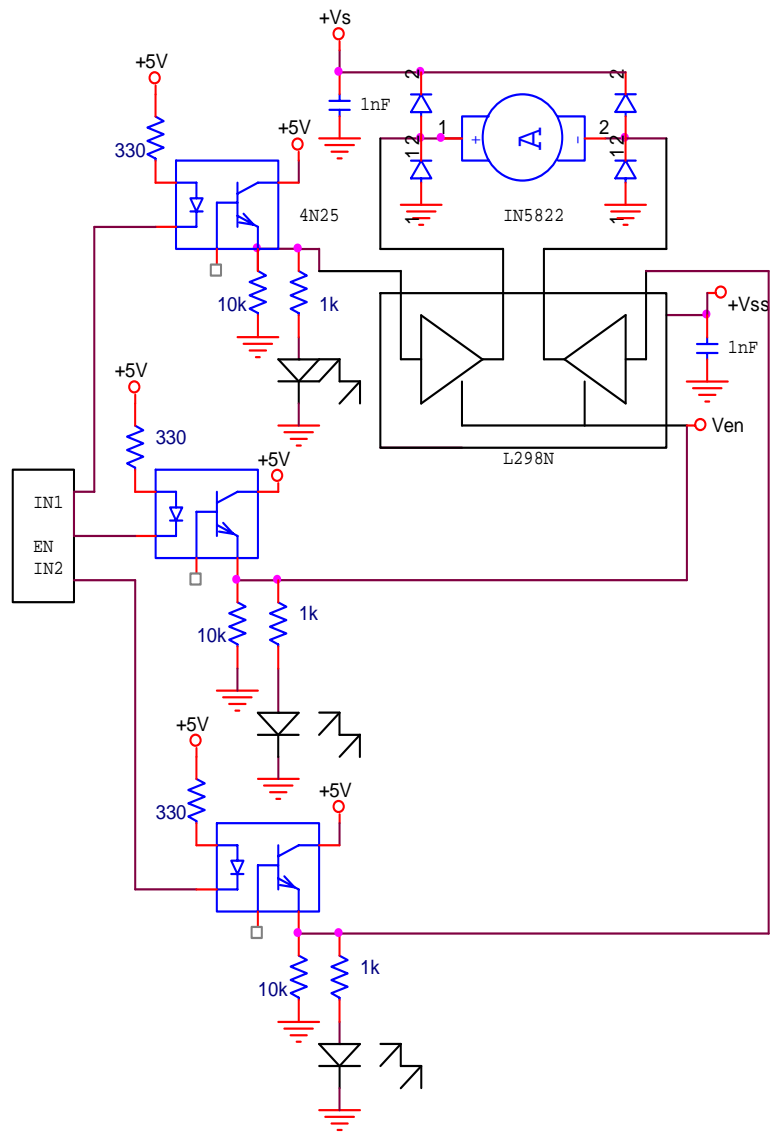

Figure 4. Motor Interface Circuit

\section{Software Design}

\section{A. Book Search}

For facilitating library user, book search software is developed using NetBeans IDE platform with embedded wireless toolkit. The platform creates an executable JAR file which can then be loaded in mobile phone for library search tasks. The software is developed for College of Engineering and Emerging Technologies with two disciplines and provides the flexibility to search the book through its title or author name. After selecting the discipline, the user can search for the desired book. The software returns the reference number assigned to that book. The user can then send an enquiry containing the reference number about the availability of the book to the central library station by using SMS service of GSM network. The library station responds by sending back the issuance and return dates of the particular book and adds the user to a queue for informing him about the book status after the return date. A sequence of steps to be carried out for book searching using mobile phone is shown in Fig. 5. In case if the user's mobile phone does not support the execution of JAR files, a GSM based searching facility is provided. In this case, a query is sent by user containing the title of book or author name to central library station in form of message. The message is preceded by keyword 'title' or 'author' whichever is applicable. A sample message transmitted is of the form "Title: The 8051 Microcontroller and Embedded Systems" or "Author: Muhammad Ali Mazidi”. Central library computer station 


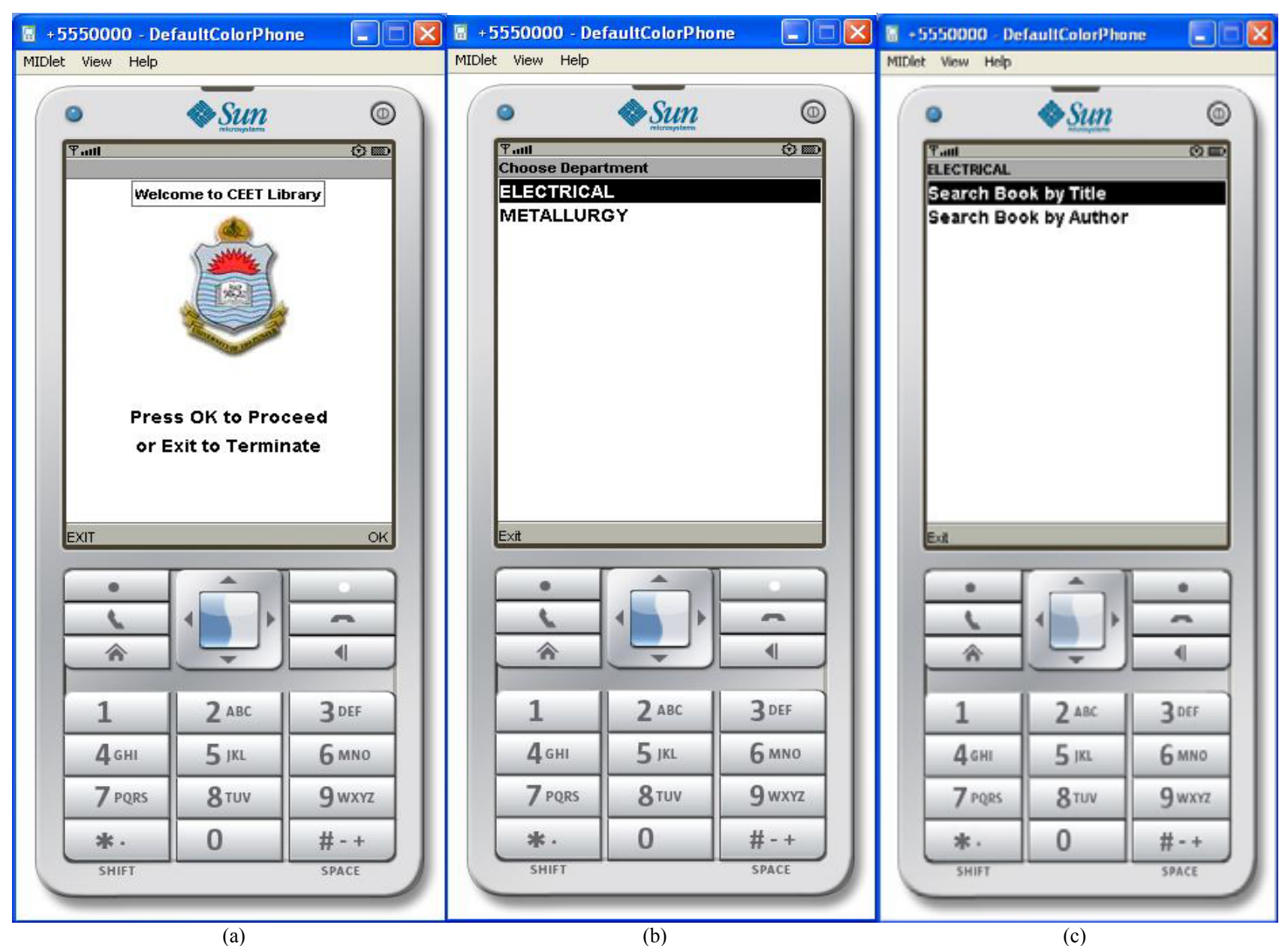

(b)

(c)

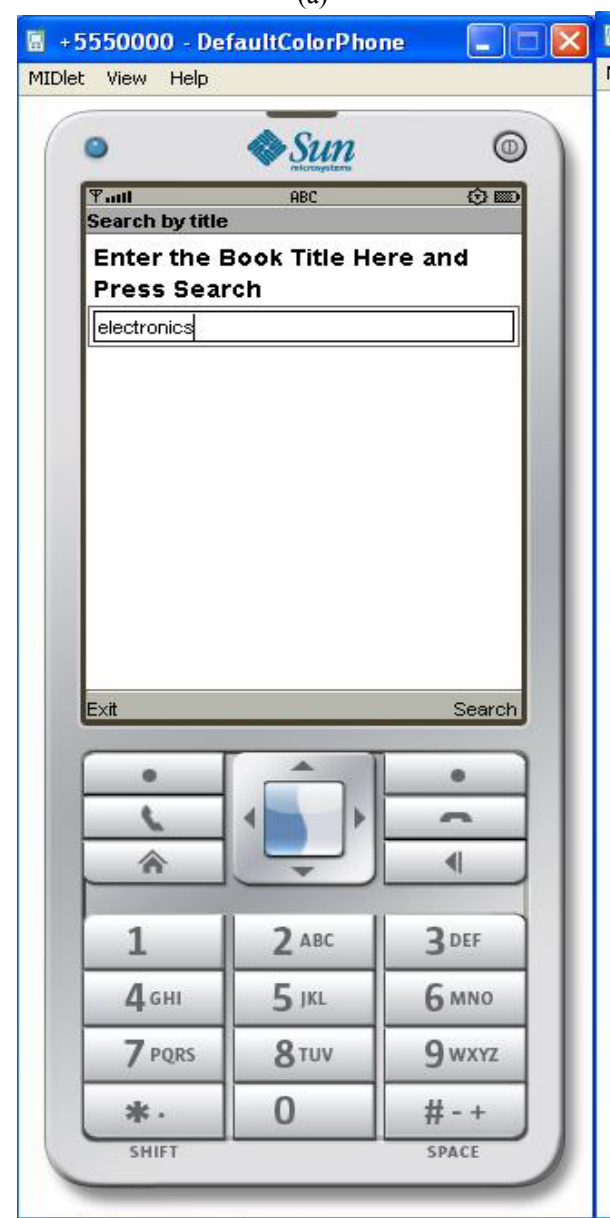

(d)

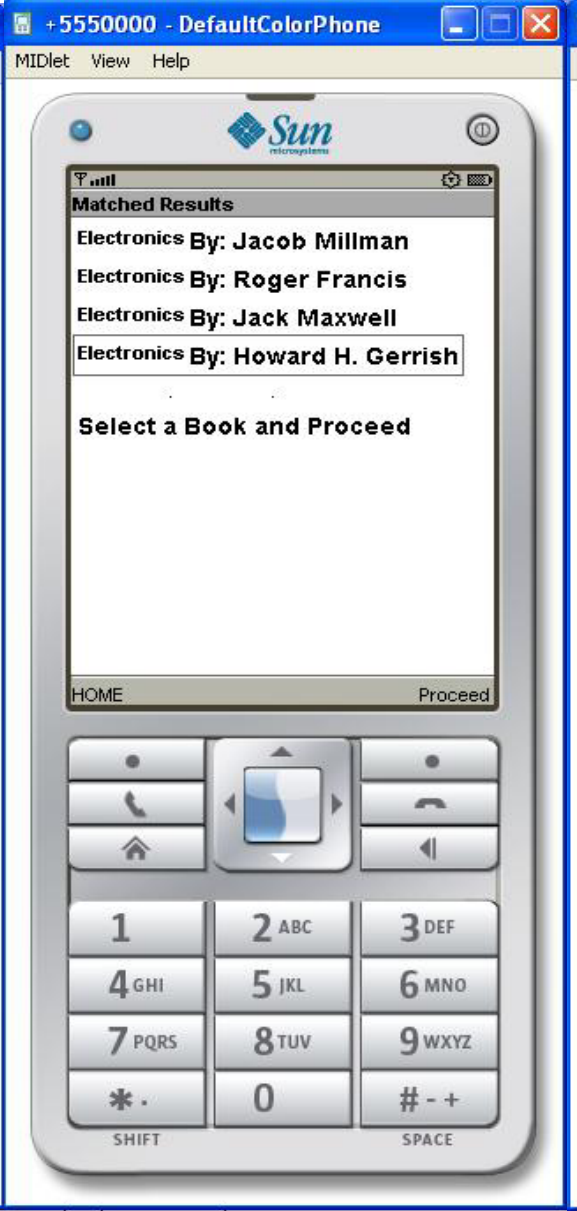

(e)

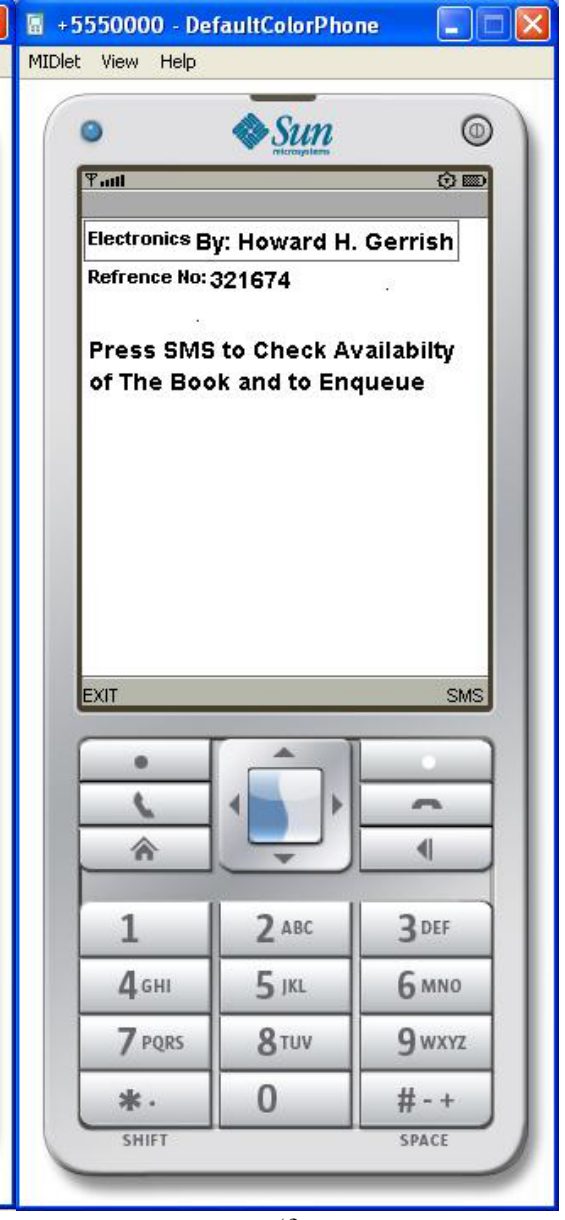

(f)

Fig. 5. (a)-(f) Sample Execution Steps for Library Search Software 
receives the message through GSM modem connected to its serial port. After processing the message, central station informs the user about the location and code number of the book. A sample message transmitted by the small scale library station is of the form "12-3" where the first two digits represents the shelf number while the third digit denotes the book position in that shelf. Sometimes the database returns more than one results. In this case the search can be refined further by sending the query message containing the title, author and domain of the book. A sample message then transmitted is of the form "Title: The 8051 Microcontroller and Embedded Systems; Author: Muhammad Ali Mazidi; Domain: Electrical Engineering". If no related book is found, then a message "no book found" is transmitted to the user. If the book is found but issued to some other user, then a message containing the issuance and return dates of book is transmitted to the user. The user can then send his query on or after the return date. A sample message received by the user is of the form "Issuance date: 12-10-2009; Return date: 26-10-2009". The flow chart of book search software is shown in Fig. 6.

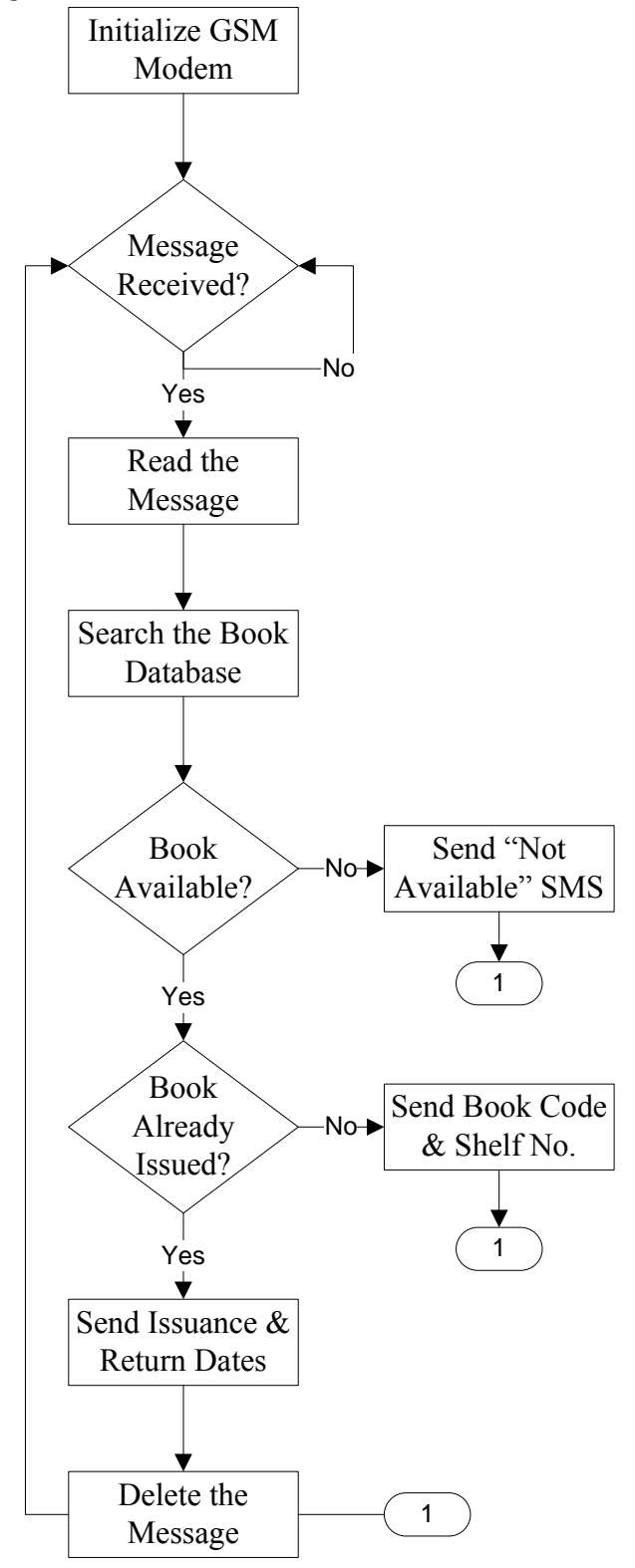

Figure 6. Book Search Flow Chart
MATLAB $®$ data acquisition toolbox is used for communicating with GSM modem through a basic set of AT commands. The command " $\mathrm{AT}+\mathrm{CMGF}=1$ " is used to set the text mode; "AT+CMGR=1,2,3" is used to read the short messages; "AT+CMGD $=1,2,3$ " is used to delete the short messages and "AT+CMGS= "Cell No." text body ctrl Z" is used to send the short message etc [7].

\section{B. Book Placement}

Data acquisition, image acquisition and image processing toolboxes of MATLAB ${ }^{\circledR}$ have been utilized for developing software for the book placement system [13].

1) Data acquisition: Parallel port of PC is used for acquiring information from sensors and controlling the motors through microcontroller. The sensor data is read with the help of 'getvalue(obj)' function from microcontroller and motor data is sent with the help of 'putvalue(obj)' function of data acquisition toolbox to microcontroller.

2) Image acquisition: Image acquisition toolbox of MATLAB ${ }^{\circledR}$ is used to acquire images from the camera. When the sensor detects a book on the base shelf, image is captured with the help of 'getsnapshot(obj)' function. A sample book image is shown in Fig. 7.

3) Image processing: After the image has been captured, image processing toolbox of MATLAB ${ }^{\circledR}$ is used to recognize the book from the pasted tag $[14,15,16,17]$.

a) Conversion to grayscale: The image acquired from the image acquisition is in RGB format which is a 3-dimensional image. It is not advantageous to process it in 3-dimensional format as the majority of MATLAB ${ }^{\circledR}$ functions deal with 2-dimensional images. So RGB image is converted to 2-dimensional help of 'rgb2gray(img)'.

b) Median filter: After converting the image to grayscale, 2-dimensional median filter is applied to the image:

$$
f(\mathrm{x}, \mathrm{y})=\underset{(\mathrm{s}, \mathrm{t}) \& \mathrm{~S}_{\mathrm{xy}}}{\operatorname{median}}\{\mathrm{g}(\mathrm{s}, \mathrm{t})\}
$$

A $3 \times 3$ template is used for implementing the median filter. This filter is selected because it has practical advantage, due to its ability to retain edges whilst suppressing the noise contamination.

c) Conversion to binary: The gray scale image is converted into binary format i.e. white and black:

where

$$
g(\mathrm{x}, \mathrm{y})=\mathrm{T}[f(\mathrm{x}, \mathrm{y})]
$$

$$
\begin{array}{cc}
\mathrm{T}(\mathrm{r})=1 & \mathrm{r} \geq \mathrm{m} \\
=0 & \mathrm{r}<\mathrm{m}
\end{array}
$$

Binary image is a 2-dimensional image. It has only two values i.e. 0 and 1. ' 0 ' represents black and ' 1 ' represents white. Now the converted image is in the form of 1's and 0 's.

d) Labeling connected components: The objects present in the binary image are labeled by selecting 4-adjacent connectivity, $\mathrm{N}_{4}(\mathrm{p})$.

$$
N_{4}\left(p_{x y}\right)=\{(\mathrm{x}+1, \mathrm{y}),(\mathrm{x}-1, \mathrm{y}),(\mathrm{x}, \mathrm{y}+1),(\mathrm{x}, \mathrm{y}-1)\}
$$

MATLAB function 'bwlabel(g,4)' is used for labeling connected components. The output of this function is a label 
matrix ' $L$ ' and a value ' $N$ ' giving the total number of conncted components in the binary image. The entries in the label matrix corresponds to a particular object. The pixles labeled as ' 0 ' in the matrix will form the background while the pixles labeled as ' 1 ' will corresspond to first object, pixels labeled as ' 2 ' will correspond to second object and so on. The image obtained after labeling is $\mathrm{h}(\mathrm{x}, \mathrm{y})$.

$$
h(\mathrm{x}, \mathrm{y})=\bigcup_{i=1}^{N} R_{i}
$$

where

$$
\mathrm{R}_{\mathrm{i}}=\left\{\left(\mathrm{x}_{\mathrm{i}}, \mathrm{y}_{\mathrm{i}}\right),\left(\mathrm{x}_{\mathrm{i}+\mathrm{hi}}, \mathrm{y}_{\mathrm{i}}\right),\left(\mathrm{x}_{\mathrm{i}}, \mathrm{y}_{\mathrm{i}+\mathrm{wi}}\right),\left(\mathrm{x}_{\mathrm{i}+\mathrm{hi}}, \mathrm{y}_{\mathrm{i}+\mathrm{wi}}\right), 1 \leq \mathrm{i} \leq \mathrm{N}\right\}
$$

e) Blob analysis: Blob analysis is used to measure different properties of image regions. The labeled matrix ' $L$ ' generated by the labeling function is used as parameter to blob analysis function 'regionprops(L, properties)'. The parameter 'properties' refers to the shape and pixel value measurements of labeled objects. Since the goal is to extract text information from the image with largest font size, it is necessary to have height, width and area measurements of the objects. A rectangle is plotted around each connected region for visualization. The labeled image with bounded rectangles is shown in Fig. 8.

f) Candidate text region: The candidate region in present case is the title of the book which is always present in larger font size compared with author(s) and publisher names. The following selection rules [18] based on the height, width and area of connected regions as well as the spacing between these rgions is used after blob analysis:

$$
\begin{gathered}
0.1<W_{i} / H_{i}<2 \\
W_{i} \times H_{i}>100 \\
0.5<H_{i} / H_{j}<2 \\
\Delta \mathrm{y}<0.2 \times \max \left(H_{i}, H_{j}\right) \\
\Delta \mathrm{x}<2 \mathrm{x} \max \left(W_{i}, W_{j}\right)
\end{gathered}
$$

where $\mathrm{W}_{\mathrm{i}}$ and $\mathrm{H}_{\mathrm{i}}$ are the width and height of extracted region; $\Delta \mathrm{x}$ and $\Delta \mathrm{y}$ are the distances between the centers of each region. The image after passing through the selection criteria is shown in Fig. 9.

$$
k(\mathrm{x}, \mathrm{y})=\text { Selection-Rules }(h(\mathrm{x}, \mathrm{y}))
$$

g) Character extraction and recognition: After filtering out undesired information from the image, characters are extracted and compared against the characters present in the lookup table using a cross-correlation method:

$$
k(\mathrm{x}, \mathrm{y}) \text { o } p(\mathrm{x}, \mathrm{y})=1 / \mathrm{MN}\left(\sum_{\mathrm{m}=0}^{\mathrm{M}-1} \sum_{\mathrm{n}=0}^{\mathrm{N}-1} k(\mathrm{~m}, \mathrm{n}) p(\mathrm{x}+\mathrm{m}, \mathrm{y}+\mathrm{n})\right)
$$

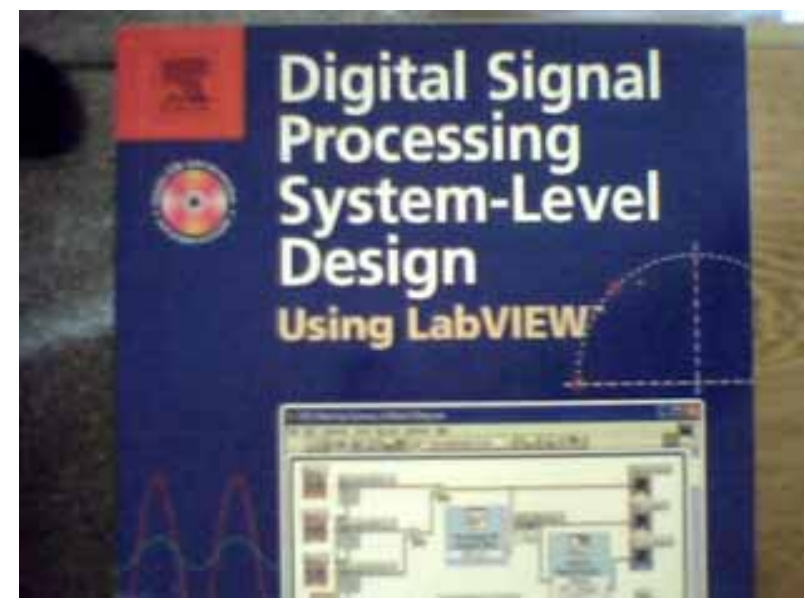

Figure 7. Image Captured by Camera
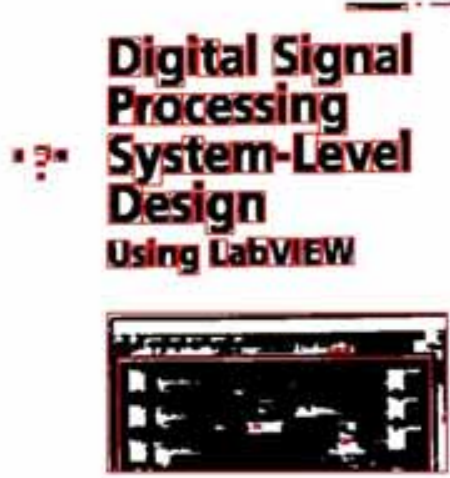

Figure 8. Image Showing Connected Regions

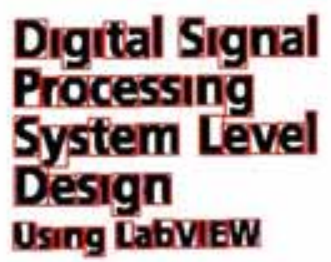

Figure 9. Processed Image with Selection Rules

MATLAB function 'corr2(A,B)' is utilized for performing cross-correlation. The function will return a real number between ' 0 ' and ' 1 ' with ' 0 ' representing no similarity ad ' 1 ' representing complete similarity. The characters after comparison are stored in a text file. The contents of the text file are then passed to search engine of library database. After the book has been found, information regarding the class and location of the book is transferred to the main program. The main program translates this information into robot movements along three axes. After placing the book, robot returns to the initial position. The flow chart of software design is shown in Fig. 10. 


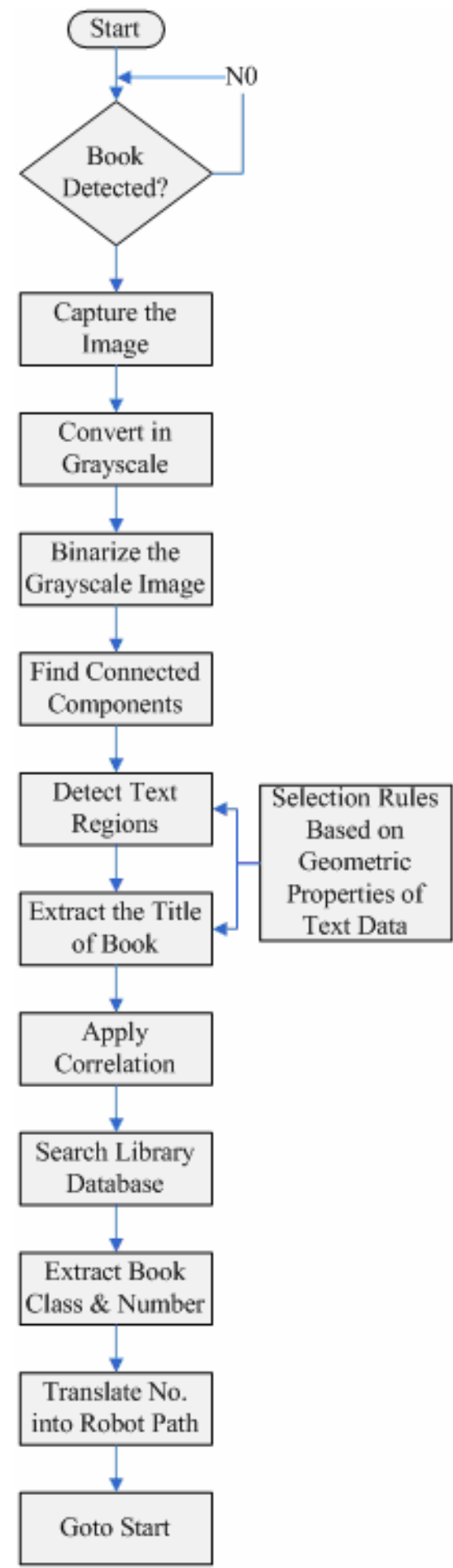

Figure 10. Flowchart Showing Software Design

\section{RESULTS}

The system is tested with different books on belt having different textured backgrounds. It is found that $80 \%$ of times, system have remained successful in placing books in the shelf. The reduced efficiency implies that used algorithm needs to be modified. Edge based text detection can be fused with the present connected components based text detection algorithm to better reject the non-text regions. Also the correlation function of MATLAB is not reliable enough for achieving best match. Instead, Quad-Trees image processing scheme can be useful for text recognition.

\section{CONCLUSIONS}

In this paper, design of book search and book placement system is presented. The book search software is developed using NetBeans IDE and executable JAR file is loaded in mobile phone. The search system tells the user about exact location of book inside the shelf. The book placement system is developed based on text extraction from captured image of front cover of the book. The title of the book is searched in database to acquire a reference number. The returned information is translated in robot movements for placing the book inside the shelf thereby ensuring its correct position.

\section{FUTURE WORK}

The present system extracts the name of the book and searches the database for its class and location. However, the location of the book can also be found from the standard tag pasted on the side of the book. Also the class of the book can be determined by utilizing text categorization techniques based on neural networks. The system can then work without library database. Besides book storage system, book retrieval system can also be automated with the help of motion sensors and digital cameras to facilitate the library users.

\section{REFERENCES}

[1] Hideaki Araki, Hirohide Haga, and Shigeo Kaneda, "Automatic Updating of a Book Storage Database in a Ubiquitous Library Information System," UIC 2006, LCNS 4159, pp.714-723, 2006.

[2] Shamsudin, T.M.W. Salami, M.J.E. Martono, W, "RFID Based Intelligent Bookcs Shelving System," $1^{\text {st }}$ Annual RFID Eurasia Conference and Exhibition, Istanbul Sep 5,6-2007.

[3] Available [online]: www.rfid-library.com

[4] Karen Coyle, "Management of RFID in Libraries," The Journal of Academic Librarianship, vol. 31(5), Sep. 2005, pp. 486-489

[5] Molnar, David and David Wagner. "Privacy and Security in Library RFID: Issues, Practices, and Architectures" in: ACM Workshop on Visualization and Data Mining for Computer Security Washington, D.C., October 25-29, 2004. pp. 210-219.

[6] Markus Aittola, Tapio Ryhanen, Timo Ojala, "Smart Library-Location Aware Mobile Library Service," Proc. $5^{\text {th }}$ Int. Symposium on Human Computer Interaction with Mobile Devices and Services, Udine, Italy 2003, pp.411-415.

[7] Available [online]:

www.d-d-s.n1/fotos-nokia/n12i_datasheet_a4_v2.pdf

[8] Available [online]:

www.atmel.com/dyn/resources/prod_documents/doc0265.pdf

[9] M. A. Mazidi, J. C. Mazidi, R. D. Mckinaly, The 8051 Microcontroller and Embedded Systems, Pearson Education, 2006.

[10] Fred G. Martin, Robotic Explorations: A Hands-On Introduction to Engineering, Prentice Hall, 2001.

[11] Available [online]: www.optrex.com

[12] Available [online]: www.alldatasheet.com

[13] Data Acquisition, Image Acquisition, Image Processing Toolboxes MATLAB $B$.

[14] Rafel C. Gonzalez, Richard E. Woods, Steven L. Eddins, Digital Image Processing using MATLABß, Perason Education, 2006.

[15] Rafeel C. Gonzalez \& Richard E. Woods, Digital Image Processing, Pearson Education Professional Publishing, 2002.

[16] Mark Nixon \& Alberto Aguado, Feature Extraction \& Image Processing, Butterworth - Heinemann Linacre House, Jordan Hill, Oxford, 2002.

[17] Habibullah Akbar, Anton Satria Prabuwono, "Webcam Based System for Press Part Industrial Inspection,” International Journal of Computer Science and Network Security, vol.8 No. 10, October 2008.

[18] N. Ezaki, M. Bulacu, L. Schomaker, "Text detection from natural scene images: Towards a system for visually impaired persons," $17^{\text {th }}$ International conference on Patteren Recognition, 2004. 